\author{
Research Article \\ www.ijrap.net (ISSN:2229-3566)
}

\title{
EFFECT OF CLINICAL YOGA PACKAGE ON QUALITY OF LIFE OF PERIMENOPAUSAL WOMEN: A RANDOMIZED CONTROLLED TRIAL
}

Sijna V P ${ }^{1 *}$, Shobhana M C ${ }^{2}$

\author{
${ }^{1}$ Assistant Professor, Department of Swasthavritta, K M C T Ayurveda Medical College, Kerala, India
}

${ }^{2}$ Professor and HOD, Department of Swasthavritta, Vaidyaratnam P S Varier Ayurveda College, Kerala, India

Received on: 25/02/21 Accepted on: 14/04/21

\author{
*Corresponding author \\ E-mail: sijnaraj@gmail.com
}

DOI: $10.7897 / 2277-4343.120240$

\begin{abstract}
Menopause is the most critical stage of women's lives. The transition phase to menopause has an important influence on women's physical, physiological and emotional wellbeing and overall quality of life. One of the major aims of health for all in the $21^{\text {st }}$ century is the improvement in the quality of life. Aim and objective is to evaluate the effect of clinical yoga packages on the quality of life of perimenopausal women. It is a randomized controlled trial conducted in the Clinical research institute of yoga and Ayurveda under the department of Swasthavritta, Vaidyaratnam P S Varier Ayurveda College, Kottakkal. A total number of 40 participants were selected by using a prepared questionnaire. The participants were randomly assigned into the study group (received yoga) $(\mathrm{n}=20)$ and control group (not received yoga) $(\mathrm{n}=20)$. Menopause specific Quality of Life questionnaire was used to assess the quality of life in both groups before and after 60 days. For the study group, a clinical yoga program was conducted for 60 days. The paired t-test was used to compare the changes within the group and the unpaired t-test was used to compare between the groups. The results showed that there was a statistically significant difference in the study group $(\mathrm{P}<0.05)$. Concluded that quality of life on perimenopausal women could be improved with a clinical yoga package for 60 days. Thus, implementing appropriate educational programs to promote the quality of life in perimenopausal women is recommended.
\end{abstract}

Keywords: Yoga, Perimenopause, Quality of Life

\section{INTRODUCTION}

Women are the most important part of family, society and community. The phase of menarche and menopause has an important influence on the women's physical, physiological, social, spiritual and emotional wellbeing and overall quality of life. The perimenopausal phase is a transition stage from the reproductive phase to the non-reproductive phase. The World Health Organization (WHO) formulates the most appropriate definition of perimenopause. The term perimenopause should include the period immediately before menopause (when the endocrinological, biological, and clinical features of approaching menopause commence) and the first year after menopause ${ }^{1}$. According to the Indian Menopausal Society, there will be a large increase in perimenopausal women in India².

In the perimenopausal stage, the ovaries gradually begin to make less estrogen which is the major hormone helping to stimulate parasympathetic nervous action. So, the fluctuation at the level of estrogen leads to the fluctuation of sympathetic- parasympathetic balance. A decline in the level of estrogen hormone leads to under-reactive parasympathetic action and over-reactive sympathetic action, and may produce many symptoms includes physical and emotional symptoms. These physical symptoms such as hot flashes, night sweats, memory loss and emotional symptoms like mood swings, depression may negatively affect women's health-related quality of life (HR-QoL) $)^{3,4}$. Factors such as older age, lack of partner and/or children, unfavorable socioeconomic conditions, low social support, presence of chronic diseases, obesity and unhealthy lifestyles are associated with HR-QO ${ }^{5}$. There is a considerable lack of awareness about the effects and the treatment of perimenopausal symptoms in women in India. For improving immediate symptoms of menopause and to manage long-term consequences, hormone therapies (HT) have been used extensively. However, unfortunately, these therapies have created new concerns about the increased risk of neoplastic of the endometrium and possibly the breast. ${ }^{6,7}$ Therefore, the contraindication associated with HT has motivated several researchers to investigate the role of alternative therapies in the safe management of perimenopausal symptoms and improving quality of life.

Yoga, the traditional Indian body-mind science has been used effectively in various health disorders affecting almost all the major organ systems. Yoga being holistic provides the multidimensional solution for overall well-being ${ }^{8,9}$. This integrated approach of Yoga helps the person to attain health by viewing the individual as a unit of body, mind, and spirit. The Pathogenesis of disease can be explained based on Pañcakōśa theory. Yoga may be particularly important to mid-life women as a safe option. It can be very effective in providing relief from physical and psychological symptoms associated with many chronic diseases and also provide good health, physical strength and enhance the overall quality of life ${ }^{10}$. The present study aims to evaluate the effectiveness of yoga on the quality of life of perimenopausal women in Malappuram district, Kerala.

\section{MATERIALS AND METHODS}

In this randomized controlled trial, simple random sampling techniques were used for the selection of participants. The total sample for the study comprised 40 of which 20 were allotted to the study group and 20 of them to the control group. Women between the age group 45-50 years with the symptoms of perimenopause were selected. Participants with a major systemic disease like DM, CVD, thyroid disorder, diagnosed fibroid 
uterus, psychotic complaints, and those who have attained surgical menopause were excluded. Formal approval was obtained from the Institutional ethical committee (Approval no: IEC/CL/19/14 dated 27.5.2014). Both written and verbal information about the study were given in the local language to women who participated in the present study.

The questionnaire for the present research study comprises two sections. Section I pertained to information regarding demographic data like age, religion, marital status, etc. Section II consisted of Standardized Menopause specific Quality of Life questionnaire (MQOL) were used to assess the quality of life consist of 48 items in 8 domains - energy, sleep, Memory, Feelings, Home life, Love life, Work activities, and social interactions on a 6 -point scale. ${ }^{11}$

The Clinical Yoga Package training class including Sukshma vyayama, Asana, Pranayama, and Meditation (Deep relaxation technique and Naadanusandhana Meditation) for 1 hour 30 minutes were given to the study. After completing the 15-day class, they were instructed to perform the Clinical Yoga Package at home for the remaining 45 days of the intervention period. The participants under the Control group are kept as a Waitlist control group. A review was conducted for both the group on the $31^{\text {st }}$ day and $61^{\text {st }}$ day.

Statistical analysis was done by using Microsoft Office 2007 Excel and GraphPad In Stat version 3.05. Data was checked, analyzed, and presented with the help of tables and graphs. An unpaired t-test was used to check the difference between groups after treatment. A paired t-test was used to assess the effect of intervention within the group. Repeated measures ANOVA was done to assess the difference between observations at pretreatment, post-treatment, and after follow-up. Post hoc analysis was done with the Tukey-Kramer Multiple Comparisons test for paired comparisons in three assessments done before, after treatment, and after follow-up.

Table 1: Comparison of Quality-of-Life Score of two groups before intervention

\begin{tabular}{|c|c|c|c|c|}
\hline \multirow{2}{*}{ DOMAIN } & \multicolumn{2}{|c|}{ BT MEAN } & \multirow{2}{*}{ t } & \multirow{2}{*}{ p } \\
\cline { 2 - 3 } & Study & Control & & \\
\hline Sleep & 21.65 & 20.85 & 0.90 & $\mathrm{P}>0.05$ \\
\hline Energy & 14.6 & 14 & 0.87 & $\mathrm{P}>0.05$ \\
\hline Memory & 12.882 & 13.29 & 0.52 & $\mathrm{P}>0.05$ \\
\hline Feelings & 40.05 & 38.85 & 0.732 & $\mathrm{P}>0.05$ \\
\hline Love life & 11.5 & 9.65 & 1.43 & $\mathrm{P}>0.05$ \\
\hline Home life & 23.75 & 22.4 & 1.31 & $\mathrm{P}>0.05$ \\
\hline Work activities & 23.5 & 24.65 & 0.60 & $\mathrm{P}>0.05$ \\
\hline Social life & 18.3 & 14.3 & 3.61 & $\mathrm{P}<0.01$ \\
\hline Total & 166.4 & 157.95 & 1.59 & $\mathrm{P}>0.05$ \\
\hline
\end{tabular}

Table 2: Comparison of Quality-of-Life Score of two groups after intervention

\begin{tabular}{|c|c|c|c|c|}
\hline \multirow{2}{*}{ DOMAIN } & \multicolumn{2}{|c|}{ AT MEAN } & \multirow{2}{*}{ p } & p \\
\cline { 2 - 3 } & Study & Control & & \\
\hline Sleep & 19.25 & 21.3 & 3.74 & $\mathrm{P}<0.001$ \\
\hline Energy & 12.8 & 14.15 & 3.19 & $\mathrm{P}<0.01$ \\
\hline Memory & 13.9 & 13.25 & 1.57 & $\mathrm{P}>0.05$ \\
\hline Feelings & 31.7 & 40.15 & 7.27 & $\mathrm{P}<0.001$ \\
\hline Love life & 12 & 9.9 & 0.37 & $\mathrm{P}>0.05$ \\
\hline Homelife & 19.3 & 23.1 & 4.12 & $\mathrm{P}<0.001$ \\
\hline Work activities & 16.9 & 25.05 & 6.517 & $\mathrm{P}<0.001$ \\
\hline
\end{tabular}

Table 3: Comparison of the effect of CYP on QOL total score in both group after treatment

\begin{tabular}{|c|c|c|c|}
\hline GROUP & MEAN & T & p \\
\hline CASE & 143.92 & & \multirow{2}{*}{} \\
\cline { 1 - 2 } CONTROL & 161.55 & 7.57 & $\mathrm{p}<0.001$ \\
\hline
\end{tabular}

\section{RESULT}

The mean age of the study group was 48.3 and, in the control, group was 48.5 . Status shows that $30 \%$ in the study group and $25 \%$ in the controlled group were in the stage of amenorrhea and the remaining $70 \%$ in the study group and $75 \%$ in the controlled group were having still menstrual periods. $32 \%$ in the study group and $35 \%$ in the control group had normal menstruation period and $68 \%$ in the study group and $65 \%$ in the control had a problem during menstruation. It was observed that these two groups were similar in terms of menopausal characteristics and age.

As shown in Table 1, Menopause Quality of life Questionnaire, there are eight domains and a total score. The values of case and control groups before CYP were compared using an unpaired ttest and it was statistically insignificant at the level of $p>0.05$ for all the domains except Social life, which means that the two groups are comparable.

The effect of the Clinical Yoga Package on Quality of life was assessed using the Menopause Specific Quality of life questionnaire is having a Total score that is representative of all the other domains like sleep, energy, memory, feelings, love life, home life, work activities, and social life. The effect of the Clinical Yoga Package in both groups was analyzed using a paired t-test. Feelings, Work activities scores were statistically significant at the level $\mathrm{p}<0.001$ in the study group. Sleep, energy, and home life were statistically significant at the level $p<0.01$ in the study group. Memory, Love life and social life were statistically not significant at the level $p>0.05$. But in the control group, all scores were statistically insignificant. To find whether the effect was due to chance RM ANOVA was done and it was highly significant at level $\mathrm{p}<0.001$ for sleep, feelings, work activities, and home life. Energy shows statistically significant at $p<0.01$. When the effect of therapy of both the groups was compared using unpaired t-test a high statistical significance was observed $(p<0.001)$ in domains sleep, feelings, home life, and work activities and energy show statistical significance at $\mathrm{p}<0.01$ as represented in Table 2 .

When the effect of CYP was analyzed using a paired t-test in the study group, the Total score showed a statistical significance at the level $\mathrm{p}<0.001$ but was statistically insignificant in the control group. To find whether the effect was due to chance RM ANOVA (Repeated Measures ANOVA) was done and it was highly significant at level $\mathrm{p}<0.001$. This shows that the result obtained in this study was more than expected by the chance effect. When the effect of therapy of both the groups was compared using an unpaired t-test a high statistical significance was observed at the level $p<0.001$ as in Table 3. So, the Clinical Yoga Package is effective in the quality of life of perimenopausal women.

\section{DISCUSSION}

In the case of perimenopausal women, the Quality of life was closely related to Energy level, sleeping pattern, cognitive functions like memory, feelings, sexual life, home activities, work activities and their social life. These domains were mostly affected by the menopausal transitional stage. Stress affects the physical, emotional, cognitive and behavioral aspects of life thereby reducing the quality of living. Therefore, a reduction in 
stress levels can result in improvement in Quality of life and vice versa.

By practicing the Sūkşma Vyāyāma and Yōga asana in the Clinical Yoga Package is improved the regular physical activity and body flexibility. When there is an improvement in physical activity it also reflects on women's mental health and their emotional feelings and helps to increase the health-related quality of life. This statement was supported by some previous studies. A study conducted by Skrzypulec V et al in 2010 reported that regular physical activity like yoga can assist women in the management of symptomatic menopause and is associated with decreasing physical and emotional issues, associated with menopause. ${ }^{12}$ Jayabharathy et. al in 2014 concluded that combine the practices of Yoga asanas, pranayama, and meditation increase the quality of life of perimenopausal women ${ }^{13}$

Most of the women complained of disturbed sleep during this perimenopausal stage. The main reason for disturbed sleep was hormonal changes happening in this stage. During perimenopause through menopause, a woman's ovaries gradually decrease the production of estrogen and progesterone, a sleep-promoting hormone. A study done by Manjunath et. al reported that yogic meditation improved the sleep quality of menopausal women, meditation was associated with an increased short wave sleep duration and decreased Rapid eye movement sleep duration on the night following practice ${ }^{14}$. From these findings, it can be inferred that Clinical Yoga Package is effective in improving sleep quality. Fatigue can be one of the more frustrating symptoms of menopause. Its influence on the women's energy level. By practicing Prānāyāma and meditation in the Clinical Yoga Package help to oxygenate the blood, Increases the amount of Prāna bringing into the system, and activates the energy flows through the body. This statement was supported by a study done by Jeter PE et. al stated that Yoga therapy especially meditation helps the brain to release more of the positive chemicals that make the person feel better and energetics ${ }^{15}$. From these findings, we can conclude that, doing meditation and pranayama help women to attain more energy levels and improve their work activities and everyday activities.

A study done by Wooley et. al London suggested that women who practiced Yoga found reducing levels of perceived selfobjectification and increased internal bodily awareness ${ }^{16}$. Increased internal body awareness help women to improve their positive feelings and confidence level. In the present study, improvement in sleep quality, energy level, emotional feelings, work activities and home life activities resulted in a significant improvement in overall quality of life in perimenopausal women by Yoga intervention.

Stress at the physical and functional level is considered an imbalance of the neuroendocrine system may cause an imbalanced outlook at the Vijñānamayakōśa, resulting in cognitive problems. This will percolate to the Manōmayakōśa resulting in emotional and behavioral problems. It is called ādhi, which can cause imbalances at the Prānamayakōśa resulting in functional problems. This further percolates into the Annamayakōśa causing physical changes and diseases (vyādhi). Therefore, it is clear that stress is a multidimensional phenomenon and is having an impact not only on the body but also on the mind. It causes imbalances in all the Pañcakōśa and reduces the quality of life.

The different practices of Clinical Yoga Package like Nadīśuddhi Bhrāmarī Prānāyā̄ma and nādānusandhāna meditation are having a positive effect on the parasympathetic nervous system as well as the Hypothalamic Pituitary Adrenal axis, thereby reducing stress and correct the imbalances at different levels of Pañcakōśas i.e., from the gross to the subtle level ${ }^{16-18}$. So in the present study, it can be concluded that by practicing Clinical Yoga Package the participants are benefitted from the psychological level of corrections along with physical, and as a result, stress is resolved and the quality of life is improved.

\section{CONCLUSION}

Thus, the present study has shown that the practice of yoga for 8 weeks increased the quality of life of menopausal women. The present study concluded that yoga is a non-pharmacological intervention in improving menopausal women's quality of life.

\section{REFERENCES}

1. Research on menopause in the 1990s. Report of a WHO Scientific Group. World Health Organization. WHO Technical Report Series No. 866; 1996.

2. Meeta, Digumarti L, Agarwal N, Vaze N, Shah R, Malik S. Clinical practice guidelines on menopause: An executive summary and recommendations. J Mid-life Health 2013; 4: 77-106.

3. Julian, Thomas M. MD Novak's Gynaecology ( $13^{\text {th }}$ edition). Journal of Lower Genital Tract Disease: April 2003; 7 - 2: 140.

4. Satoh T, Ohashi K. Quality-of-life assessment in communitydwelling, middle-aged, healthy women in Japan. Climacteric 2005; 8: 146-153.

5. Schwarz S, Völzke H, Alte D, Schwahn C, Grabe HJ, Hoffmann W, et al: Menopause and determinants of quality of life in women at midlife and beyond: The Study of Health in Pomerania (SHIP). Menopause 2007; 14: 123-134.

6. Grodstein F, Stampfer MJ, Manson JE, et al. Postmenopausal oestrogen \& progestin use and the risk of cardiovascular disease. N Engl J Med 1996; 335: 453-61.

7. Manson J.E., Colditz G.A., Willett W.C., Speizer F.E. Stampfer MJ. A Prospective, Observational Study of Postmenopausal Hormone Therapy and Primary Prevention of Cardiovascular Disease. Annals of Internal Medicine 2000; 133(12): 933-941.

8. Sengupta P. Health Impacts of Yoga and Pranayama: A Stateof-the-Art Review. Int J Prev Med 2012; 3(7): 444-458.

9. Woodyard C. Exploring the therapeutic effects of yoga and its ability to increase the quality of life. Int J Yoga 2011; 4(2): 49-54. DOI: $10.4103 / 0973-6131.85485$

10. Nagendra HR, Nagarathna R, Shirley Telle. Yoga and Cancer. $2^{\text {nd }}$ ed. Swami Vivekananda yoga Prakashana, Bangalore 2010; 2: 10.

11. Zöllner YF, Acquadro C, Schaefer M. Literature review of instruments to assess health-related quality of life during and after menopause. Qual Life Res 2005; 14(2): 309-327.

12. Skrzypulec, V, Da browska, J. Drosdzo, A. The influence of physical activity level on climacteric symptoms in menopausal women. Climacteric: The International Journal of the International Menopause Society 2010; 13(4): 355-361.

13. Jayabharathy B, Judie A. A Prospective Randomized Interventional Study to Evaluate the Effect of Yoga on Quality of Life of Menopausal Women: GJRA 2014; 3(7): 207-210.

14. Manjunath NK, Telles S. Influence of Yoga and Ayurveda on self-rated sleep in a geriatric population. Indian J Med Res 2005; 121(5): 683-690.

15. Jeter PE, Nkodo AF, Moonaz SH, Dagnelie G. A systematic review of yoga for balance in a healthy population. J Altern Complement Med 2014; 20(4): 221-232.

16. Woolley, Lauren M. The relationship of yoga, selfobjectification, disordered eating, and depressed mood in 
college-aged women. Diss. Abstr. Int. Sect. B Sci. Eng.; 2009-08.

17. K. Raman, A matter of health, in Integration of Yoga and Western Medicine for Prevention and Cure, East-west Books, Chennai, India; 1998.

18. Tran MD, Holly RG, Lashbrook J, Amsterdam EA. Effects of Hatha Yoga practice on the health-related aspects of physical fitness. Prev Cardiol 2001; 4: 165.

\section{Cite this article as:}

Sijna V P and Shobhana M C. Effect of Clinical Yoga Package on Quality of life of Perimenopausal Women: A Randomized Controlled Trial. Int. J. Res. Ayurveda Pharm. 2021;12(2):25-28 http://dx.doi.org/10.7897/2277-4343.120240

\section{Source of support: Nil, Conflict of interest: None Declared}

Disclaimer: IJRAP is solely owned by Moksha Publishing House - A non-profit publishing house, dedicated to publishing quality research, while every effort has been taken to verify the accuracy of the content published in our Journal. IJRAP cannot accept any responsibility or liability for the site content and articles published. The views expressed in articles by our contributing authors are not necessarily those of IJRAP editor or editorial board members. 